National Mapping Program

Technical Instructions

Data Users Guide 6

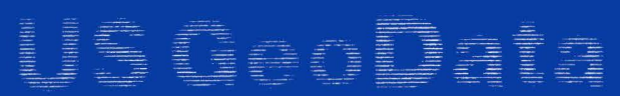

\title{
Geographic Names \\ Information System
}

\section{Data Users Guide}




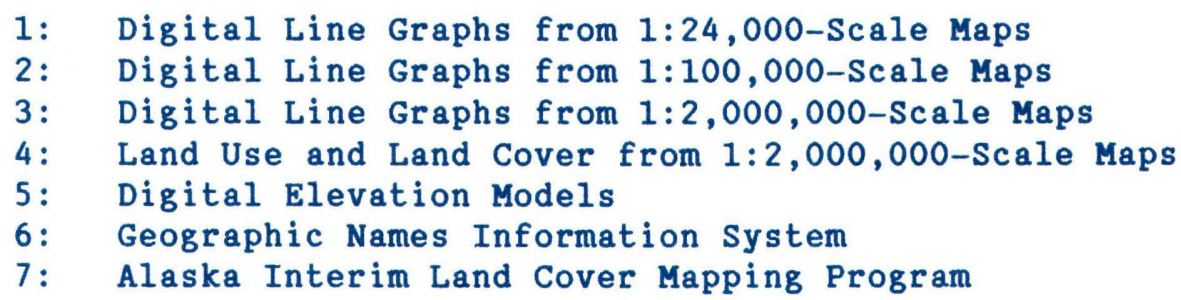

Data Users Guides 1-7 replace Geological Survey Circular 895 B-G.

Questions regarding availability and ordering of US GeoData (all types of digital cartographic and geographic data produced and distributed by the U.S. Geological Survey) should be addressed to:

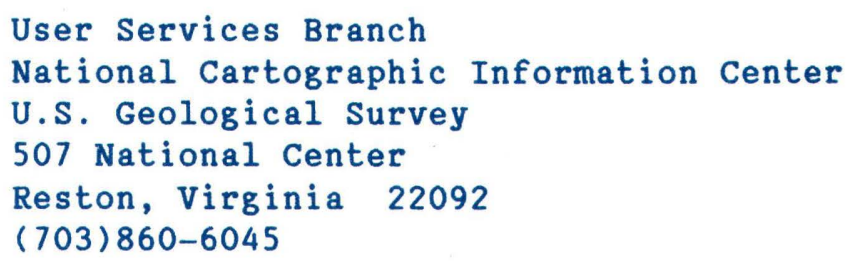

Technical questions and comments should be addressed to:

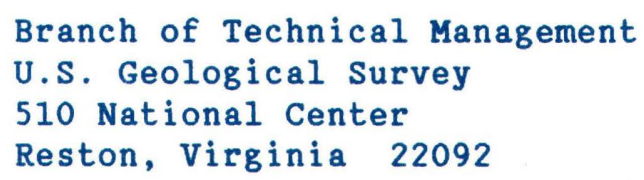


UNITED STATES

DEPARTMENT OF THE INTERIOR

U.S. GEOLOGICAL SURVEY

GEOGRAPHIC NAMES INFORMATION SYSTEM

Data Users Guide 6 
First printing, 1985

Second printing (revised), 1987 


\section{PREFACE}

This Data Users Guide is the result of the efforts of a number of people who have contributed to the research, development, and implementation of the Geographic Names Information System (GNIS). Roger L. Payne prepared and wrote this Data Users Guide, which is designed to provide a description of the data in each of the data elements of the four data bases of GNIS. The GNIS program, which includes the automated names system and the National Gazetteer program, is a coordinated effort under the direction of Donald J. Orth, Chief of the Branch of Geographic Names. The automated system was initially developed by Sam Stulberg and Roger L. Payne. System enhancement and software development is coordinated by Judy J. Stella, head programmer for GNIS, and special projects coordinator is Louis A. Yost IV. Coordination of the research and compilation of certain gazetteers is directed by Robin D. Worcester with research assistance and support from Jon Campbell, Linda S. Davis, and Nancy Engel. 



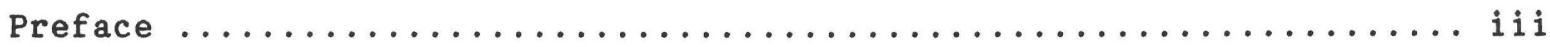

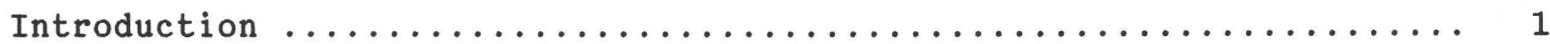

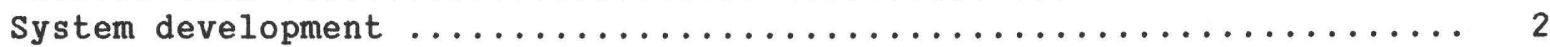

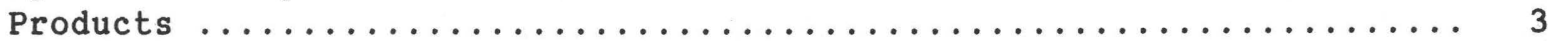

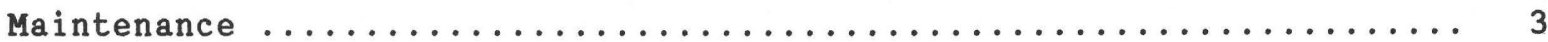

Description of the data bases $\ldots \ldots \ldots \ldots \ldots \ldots \ldots \ldots \ldots \ldots \ldots \ldots \ldots$

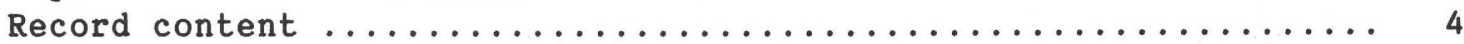

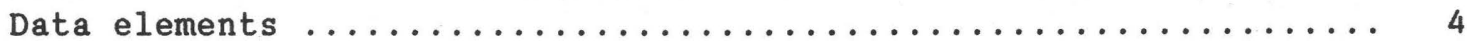

National Geographic Names Data Base ................... 4

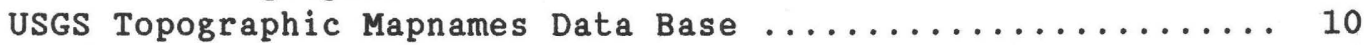

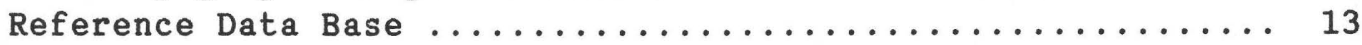

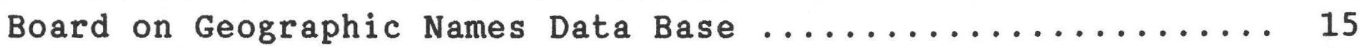

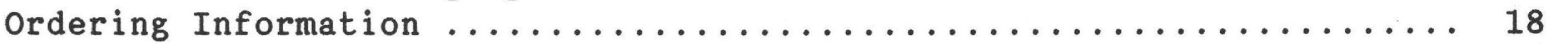

Appendix A. Categories of named features not yet included

in the Geographic Names Information System ......... 22

B. Geographic Names Information System feature

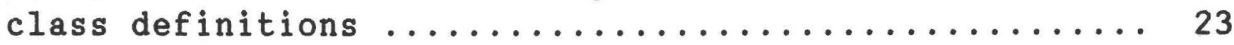

C. Parenthetical descriptors used with names ........... 28

D. Sample records from the National Geographic

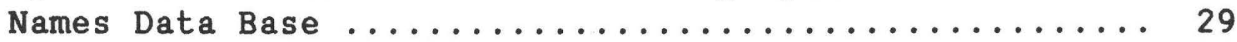

TABLES

Page

Table 1. Labels and data elements from the National

Geographic Names Data Base ...................... 5

2. Labels and data elements from the USGS

Topographic Mapnames Data Base .................... 10

3. Labels and data elements from the Reference

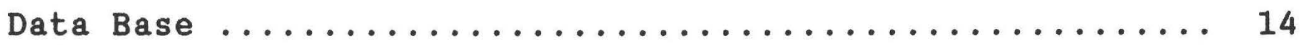

4. Labels and data elements from the Board on Geographic Names Data Base ........................ 15 



\section{INTRODUCTION}

The National Cartographic Information Center (NCIC) distributes digital cartographic/geographic data files produced by the U.S. Geological Survey (USGS) as part of the National Mapping Program. Digital cartographic data files may be grouped into four basic types. The first of these, called a Digital Line Graph (DLG), is the line map information in digital form. These data files include information on planimetric base categories, such as transportation, hydrography, and boundaries. The second type, called a Digital Elevation Model (DEM), consists of a sampled array of elevations for a number of ground positions that are usually at regularly spaced intervals. The third type is Land Use and Land Cover digital data which provides information on nine major classes of land use such as urban, agricultural, or forest as well as associated map data such as political units and Federal land ownership. The fourth type, the Geographic Names Information system, provides primary information for all known places, features, and areas in the United States identified by a proper name.

The digital cartographic data files from selected quadrangles currently available from NCIC include the following:

- Digital Line Graphs (DLG's)

$-1: 2,000,000-$ scale maps

--7.5- and 15-minute topographic quadrangle series

$--1: 100,000-$ scale quadrangle series

- Digital Elevation Models (DEM's)

--7.5-minute topographic quadrangle series

--1-degree quadrangle coverage

- Land Use and Land Cover digital data

$--1: 250,000-$ and 1:100,000-scale land use and land cover and associated maps

$--1: 250,000-s c a l e$ Alaska Interim Land Cover Maps

- Geographic Names

Any use of trade names and trademarks in this publication is for identification purposes only and does not constitute endorsement by the U.S. Geological Survey. 
The digital data are useful for the production of cartographic products such as base maps and for various kinds of spatial analysis. A major use of these digital cartographic/geographic data is to combine them with other geographically referenced data, enabling scientists to conduct automated analyses in support of various decision making processes.

This document describes the Geographic Names Information System (GNIS), which was developed by the U.S. Geological Survey (USGS) to meet major national needs regarding geographic names and their standardization and dissemination. Information in the system can be retrieved, manipulated, arranged, and analyzed to meet the needs of a wide variety of users for either research or application. Primarily, GNIS was designed to:

1. Assist in establishing uniform geographic name usage throughout the Federal Government in cooperation with the U.S. Board on Geographic Names;

2. Provide an index of names found on Federal, State, and other maps;

3. Eliminate duplication in time and money spent by Government agencies, industry, and institutions to organize similar data files for specific needs;

4. Provide an interface for integrating data from other systems for multidisciplinary use;

5. Provide for standardization of data elements and their coded representation for use within the information processing community; and

6. Meet Federal public information requirements prescribed by law.

\section{SYSTEM DEVELOPMENT}

The GNIS is currently composed of four data bases:

1. National Geographic Names Data Base,

2. USGS Topographic Mapnames Data Base,

3. Reference Data Base, and

4. Board on Geographic Names Data Base.

Research and initial compilation of data for the GNIS were begun in 1968 when geographic names data for Massachusetts were collected and stored in a computerized file. In 1976, geographic names data for Kansas and Colorado were collected as a pilot project to determine the feasibility of compilation on a national scale. After analysis and a favorable evaluation of this pilot project, geographic names data for the remaining States and territories were compiled from 1978 through 1981. The initial compilation, or Phase $I$, is now complete, and the system includes records or entries for most named features on all of the maps in the USGS topographic map series except roads and highways. As maps of the largest scale available were used during the initial compilation, the majority of 
the names were compiled from 1:24,000-scale, 7.5-minute topographic maps. When there were no published 7.5-minute maps or advance copies with names available, 15-minute maps were used; when there was no coverage by either series of maps, 1:250,000-scale maps were used.

After Phase I data compilation, the geographic names records in each State file were edited by comparing the computer files with the accumulated records of the U.S. Board on Geographic Names (BGN) on a one-to-one basis. When the initial edit of the geographic names in a state file was completed, the corrections were made, and other information such as variant names and BGN data were added.

Optimum use and effectiveness of the automated names system requires that the names of features not recorded on topographic maps be added, together with specific types of feature names excluded from compilation during Phase I (see Appendix A) and other names of importance to researchers and users, such as historical and variant names. The systematic collection of names from other sources, including maps, charts, and texts, as well as historical sources, is termed Phase II.

\section{PRODUCTS}

A standard report is available for each state and territory which lists each name and associated information alphabetically as a 132-character line entry designed to provide information from most of the locative data elements. This report is available in the form of bound listings, microfiche, and magnetic tape. Specialized reports tailored to the individual needs of the user are also available. A more formal publication is The National Gazetteer of the United States of America, published as U.S. Geological Survey Professional Paper 1200. The geographic names in each State and territory will be published as separate volumes in the gazetteer series when Phase II compilation and edit have been completed. An online version of the data base is available for interactive access by information specialists of the Geological Survey. Use of the GNIS information is varied, and usually has a wide range of application. However, broad categories of use include local transportation planning, regional planning, product marketing, site selection and analysis, emergency preparedness, genealogical research, and generally solving toponymic problems requiring the use and analysis of geographic names.

\section{MAINTENANCE}

The GNIS is maintained by the USGS National Mapping Division. Each regional mapping center compiles and formats new name data and minor corrections, which are electronically transmitted to the GNIS staff for a final check before the data are entered into the system. The U.S. Board on Geographic Names transmits information directly to the system concerning the resolution of geographic names found to be in conflict on Federal sources. A series of checks and balances assures integrity and security so that all users can retrieve and use data with confidence. 
Maintenance is continual. All users have retrieval capability, but only the GNIS staff has the capability to alter, add, or remove information. The system resides and operates on a mainframe computer.

DESCRIPTION OF THE DATA BASES

A record consists of a name and its associated data. Each record is given a unique eight-digit number. The first two digits of this number identify the file within the data base in which the record exists. The remaining six digits identify the specific record within the file.

\section{Record Content}

The following tables list the data elements and their associated labels in each of the four data bases, followed by a detailed explanation of each data element. Sample records from one of the data bases, the National Geographic Names Data Base, are given in Appendix D. To properly search and retrieve information, the user must be thoroughly familiar with the nature of the data in the system, as well as the commands.

\section{Data Elements}

\section{National Geographic Names Data Base}

The National Geographic Names Data Base is the primary and largest data base in GNIS. It contains 60 files representing each state, territory and outlying area, the District of Columbia, and certain specialized files. Each state file contains, as a minimum, the names compiled from the USGS topographic map series, but many state files contain information from other source materials. Eventually, all state and territory files will contain information from other sources. There are presently two files for the State of Alaska. One file is the digital version of the Dictionary of Alaska Place Names, published as U.S. Geological survey Professional Paper 567 in 1967, and includes descriptions and historical notes. The other Alaska file is the version digitized from the latest maps. Eventually, these two versions will be combined into one Alaska file. There are currently two topical files that contain thematic data on a national scale. One of these files contains entries for most of the populated places in the United States, while the second file contains about 50,000 of the most well-known populated places and physical features in the United States and represents an abridged version of the other state files.

The following data element descriptions are designed to provide the necessary information for understanding and retrieving data. Table 1 lists each data element and the appropriate label abbreviation used when retrieving or requesting information. 
Table 1.--Labels and data elements from the National Geographic Names Data Base

\begin{tabular}{|c|c|}
\hline Label & Data Element \\
\hline BIBLIO & BIBLIOGRAPHIC CODE \\
\hline BGN & BGN DECISION YEAR \\
\hline CENCODE & CENSUS PLACE CODE \\
\hline COUNTY & COUNTY NAME \\
\hline DATE & YEAR OF NAME ORIGIN \\
\hline DESCR & DESCRIPTION \\
\hline DESIG & TYPE OF FEATURE \\
\hline ELEV & ELEVATION (FT) \\
\hline FIPS 55 & FIPS 55 PLACE CODE \\
\hline HEADS & SOURCE OF FEATURE (LATLONG) \\
\hline HIST & HISTORICAL NOTE \\
\hline LATLONG & GEOGRAPHIC COORDINATES \\
\hline LOC & STATE/COUNTY FIPS CODE \\
\hline MAP & GNIS MAP NUMBER \\
\hline MAPNAME & MAP OR CHART NAME \\
\hline NAME & FEATURE NAME \\
\hline NUMBER & ID NUMBER \\
\hline POP & POPULATION (1980) \\
\hline QUAD & USGS QUADRANGLE CODE \\
\hline SIZE & SIZE \\
\hline SPDESIG & SPECIAL DESIGNATOR (DETAILED) \\
\hline SPEC & SPECIAL CODES \\
\hline STATE & NAME OF STATE (FIPS) \\
\hline STATUS & FEDERAL STATUS \\
\hline STR & SECTION, TOWNSHIP, AND RANGE \\
\hline VAR & VARIANT NAME(S) \\
\hline ZIP & POSTAL ZIP CODE \\
\hline
\end{tabular}

BIBLIO - A variable-length alphanumeric coded entry that references the source for each name record in the file that was not compiled from the USGS topographic map series during the initial compilation. The first two characters of the code are the alphabetical state Federal Information Processing Standards (FIPS) code, followed by a hyphen and an $M$ or a $T$ corresponding to Map or Text respectively. The $M$ or $T$ is followed by one or more digits that are a specific reference to a fully documented and annotated bibliographic entry describing the source from which that name was obtained. Some entries may begin with the characters US which means that this source is used for each state and territory file. If the source used is an atlas or text, the code will be followed by a slash (/) and a specific reference to a map or page in the source. The complete bibliographic entry is located in the Reference Data Base. The absence of a code indicates that the name was compiled during Phase I (1978-1981) from the most current largest scale USGS topographic map. Information in this element will be added as each volume of the gazetteer series (Professional Paper 1200) is published. 
BGN - A variable-length alphanumeric field that represents, if present, the year a decision was rendered by the U.S. Board on Geographic Names (BGN) because the name was found to have conflicting usage on Federal sources and required special research. A special entry is the word "Statutory" followed by a space and the year, which indicates a name approved by an act of Congress. There may be multiple dates for the same name, with each entry separated by a blank. Multiple dates mean that the BGN had to revise a former ruling because the name changed or the application of the name to the feature changed.

CENCODE - A four-digit numeric field that represents the place code as assigned by the U.S. Bureau of the Census. This code is available only in the National Populated Places file.

COUNTY - The variable-length upper- and lower-case name that represents the primary civil division(s) (county level) in which the feature is 10cated. Multiple county entries are separated by a blank, and the order for linear features is from mouth to source while the order for areal features is generally from the center outward. If the county is in another state, then the two-character alphabetic FIPS code is in parentheses after the county name.

DATE - A variable-length alphanumeric entry containing the year or approximate year (if known) that the feature name came into being. This data element may contain some text describing the circumstances of the naming. Information is present only on a very limited basis.

DESCR - Variable-length upper- and lower-case text that defines the situation, or relative position, to nearby features and to at least one close, well-known feature, usually a major town or city. Distances are provided, as well as the names of all major and minor civil divisions associated with the feature. The data element is available in the Alaska Dictionary and Massachusetts files, and other files on a limited basis.

DESIG - A variable-length lower-case alphabetic element that is designed to group similar features into broadly designated categories to facilitate search and retrieval. Appendix B contains a list of categories and their definitions. The Reference Data Base contains a cross-reference to one of these broad categories for every generic or type of feature thus far encountered in the compilation of the National Geographic Names Data Base.

ELEV - A variable-length field that gives the height above or depth below sea level, in feet, of the highest point or lowest point respectively. For those files that have not undergone Phase II data compilation, an entry is present only if a published elevation was directly associated with the feature on the topographic map. The Alaska Dictionary file also contains some ranges of elevations separated by a hyphen. State and territory files that have been completed through Phase II contain interpolated elevations for populated places and summits, and some other features compiled during Phase II may have interpolated elevations. Metric conversion will be accomplished at a later date. 
FIPS 55 - A five-digit numeric field that contains the place code of populated places as assigned by the National Bureau of Standards. The codes are available only in the National Populated Places file.

HEADS - A fixed-length alphanumeric field that indicates the source of linear features. The format is identical to that of the geographic coordinates in the data element LATLONG; however, there is only one source coordinate. The source coordinates correspond to the last entries in the data elements MAPNAME and QUAD. The source of a linear feature is not always indicated by the name placement on the map; therefore, the guideline applied was that the source of linear features not properly identified by name placement, textual description, or any other indicative variable should be taken to the source of the longest, straightest drain. This guideline is in accordance with the policies of the U.S. Board on Geographic Names.

HIST - A variable-length upper- and lower-case text that provides as much information as is available from all known reputable sources about the physical and cultural history of a named feature. Additionally, special attention is given to name origin, if known, and detail is provided for background research. At present, the element contains information only for the Alaska Dictionary and Massachusetts files, as well as limited entries for those state files that have been completed through Phase II compilation.

LATLONG - An entry that contains the official geographic coordinates in a variable-length alphanumeric field with each coordinate compressed into and fixed at a 15-character format. Latitude and longitude are to degrees, minutes, and seconds, and each is followed by a one-character alpha directional indicator. If the degrees of longitude are less than 100, a leading zero is present. The first coordinate in this element is termed the primary coordinate. In the case of areal features, they represent the approximate center of the feature, while the primary coordinates of linear features represent the mouth. The mouth is where the feature joins another feature, ends in a delta or is an alluvial fan, or no longer has a discernible channel or trough-like character. All subsequent coordinates in this element are termed secondary coordinates and identify the feature on each 7.5-minute topographic map on which it is located. The location of the secondary coordinates is simply anywhere on the feature on the topographic map with which it is associated. The geographic coordinates are accurate to within \pm 5 seconds of latitude or longitude. The guideline for digitizing areal features requires that primary coordinates be taken in the center, but the location of the center of a large city is sometimes somewhat subjective. Additional guidelines for use in determining the placement of the primary geographic coordinates of large populated places include the location of the city hall or town hall, main post office, main library, central business district, or main intersection.

The primary coordinates correspond to the first entry in the data elements MAPNAME and QUAD. All subsequent coordinates correspond on a one-to-one basis with the entries in the data elements MAPNAME and QUAD. Also, multiple coordinates for linear features are in order from mouth to source while multiple coordinates for areal features are generally listed from the center outward. 
LOC - A variable-length alphanumeric field that contains one or more fivedigit FIPS codes referring to the state and county or county equivalent. The first two digits of each code refer to the state or territory and the last three digits refer to the county, parish, municipio, or other civil division. Codes for all counties in which a feature is located are present with multiple entries separated by a blank. Multiple codes are ordered from mouth to source for linear features and generally from the center outward for areal features. All codes are numeric except when the State or territory borders a foreign country, in which case the appropriate two-character alphabetical FIPS code is given -- CA for Canada, MX for Mexico, UR for the Soviet Union, UK for the United Kingdom, and WS for Western Samoa.

MAPNAME - The variable-length upper- and lower-case entry that reflects the mapname exactly as it appears on the USGS topographic map. If the feature falls completely outside the bounds of USGS topographic map coverage, a reference to the source map used in compilation is present. The entries in this data element correspond to the entries in LATLONG and QUAD. If the coordinates are located outside the state or territory, the name of the map followed by a blank and the two-character alphabetic state FIPS code in parentheses are recorded.

NAME - A variable-length upper- and lower-case alphanumeric entry that contains the official geographic name, which in most cases includes a generic that indicates the feature type. Some entries are followed by a space and an asterisk, which denotes a diacritical mark somewhere in the name. This arrangement is temporary and will soon be replaced by the inclusion of the appropriate diacritical mark and the removal of the asterisk. In some cases the generic part of the name may be in the first position, followed by the specific part. In those cases, the position of the generic within the name is reversed; for example, Mount saint Helens becomes Saint Helens, Mount. The generic, however, is not reversed if the feature is a populated place or if the specific part of the name contains an Arabic number. Additionally, if the definite article occurs in initial position in the name, it is reversed; for example, The Plains becomes Plains, The, and La Mesa becomes Mesa, La. Some names are followed by a parenthetical entry that provides additional information about the name; for example, Gold Town (historical site), Seven Springs (flowing), Big Flat (mud). Appendix C contains a complete listing of parenthetical entries encountered thus far.

NUMBER - An eight-digit number that is the unique identifier of each feature and its associated information. The first two digits correspond to the state numeric FIPS code. Data is present only for incorporated places, and this is the only data element that must exist for each record and is for GNIS internal use.

POP - A variable-length numeric field containing Census population figures for named features in the feature class categories of populated place and, if applicable, locale. Data is present only for incorporated places, and this information is available only in the national populated places file. 
QUAD - A fixed-length alphanumeric field that contains eight characters of the USGS topographic map coding system. The first five digits represent the degrees of latitude and longitude of the particular $1^{\circ}$ latitude $x 1^{\circ}$ longitude square in which the map is located, followed by a hyphen and a specific alphanumeric code identifying one of the sixty-four 7.5minute cells in the $1^{\circ} \times 1^{\circ}$ square. The rows of the square are coded $A$ through $\mathrm{H}$, and the columns are coded 1 through 8 , each beginning in the southeast corner of the $1^{\circ} \times 1^{\circ}$ area.

SIZE - A short variable-length alphanumeric phrase that gives the length of linear features and the width of areal features in English units. This element is used in the Alaska Dictionary and Massachusetts files, and is being utilized in the compilation of Phase II data.

SPDESIG - A variable-length alphanumeric data element. This element is used to indicate category of responsibility for administrative features such as Federal, State, and municipal. The element is also used to provide special information about the feature. For example, certain categories such as airports may be listed here as privately owned, and commercial places are so indicated as well. Information regarding whether populated places are incorporated or not may be found in this data element. This element is active in state and territory files that have completed Phase II compilation.

SPEC - A special numeric reference code that relates to specific characteristics of the named feature such as source material; language of origin; unusual characteristics; number of words in the name; whether descriptive, associative, or comparative; or any other known characteristic of the name. This data element is currently available in the Massachusetts file only, but research is underway to provide a standard format conducive to national and multidisciplinary utilization.

STATE - A two-character alphabetic element that contains the standard FIPS abbreviation for state and territory names. The element is used only in national topical files.

STATUS - A variable-length alphabetic entry that provides the Federal standing of each name in the data base. Entries indicate whether the name is official according to the policies of the U.S. Board on Geographic Names (BGN); has had special research and consideration by the Board (BGN YEAR); is official by an act of Congress (US YEAR); is administrative according to Federal, State, or local organizations (ADMIN); or is unofficial (UNOFF) and not within the purview of the BGN or any other administrative body.

STR - A variable-length alphanumeric data element that identifies the appropriate section, township(s), and range(s), and principal meridian in which the feature occurs. If the feature is in more than one section, only the township(s) and range(s) and principal meridian are given. The township and range system was established in the late 18th century to systematically divide Federal lands. The original 13 states and Vermont, Tennessee, Kentucky, West Virginia, Maine, Texas, Hawaii, part of Ohio, and all territories are not included in the township and range system. The element is available after Phase II compilation. 
VAR - A variable-length upper- and lower-case field containing any other current name, former name, or former spellings of the current official name. If more than one variant is present, they are arranged alphabetically and separated by a comma and a blank. Additionally, if the BGN rendered a formal decision for what is now a variant, the year of that decision is given in parentheses following the variant name with which it is associated. A variant obtained from a source other than the BGN is followed by a code in parentheses that is a reference to a complete annotated bibliography of the source. The code may also be followed by a map or page number, if the variant was obtained from an atlas or a text. All complete annotated bibliographies reside in the Reference Data Base.

ZIP - Contains the five-digit postal zip code associated with populated places and, if applicable, locales. This element will be available only in the national populated places file.

\section{USGS Topographic Mapnames Data Base}

The USGS Topographic Mapnames Data Base contains 57 separate files; the $1: 24,000-s c a l e$ topographic mapnames for each State and territory comprise 56 of the files, and a separate file contains mapnames and other information about $1: 100,000$ - and 1:250,000-scale topographic maps.

The following data element descriptions are designed to provide the necessary information for understanding and retrieving data. Table 2 lists each data element and the appropriate data element abbreviation (label) used when retrieving data.

Table 2.--Labels and data elements from the USGS Topographic Mapnames Data Base

COORD
COUNTY
FIPS
HIST
MAP
NAME
NUMBER
QUAD
SCALE
STATE
XNAME
250

COORD

COUNTY

FIPS

HIST

NAME

NUMBER

QUAD

SCALE

250

\author{
LAT/LONG (SE CORNER) - \\ QUAD SIZE (MINUTES) \\ COUNTY NAME \\ STATE ALPHA FIPS CODE \\ FORMER QUADRANGLE NAME(S) \\ GNIS MAP NUMBER \\ QUADRANGLE NAME \\ ID NUMBER \\ USGS QUADRANGLE CODE \\ QUADRANGLE SCALE \\ QUADRANGLE STATE(S) \\ $7.5 \times 15$ MINUTE MAP NAME \\ QUADRANTS 250000 SERIES
}


COORD - Contains an 11-character alphanumeric code that represents the latitude and longitude of the southeast corner of the cell, or the northeast corner of the cell in American Samoa and the southwest corner of the cell in Guam and certain Alaska maps. The coordinates give degrees and minutes followed by the appropriate directional indicator. Quadrangles ending in 30 seconds are rounded down to the next minute as shown on each topographic map, and longitude of less than $100^{\circ}$ is preceded by a leading zero. The file of $1: 100,000$ - and 1:250,000-scale maps differs somewhat in that the directional identifier precedes the coordinate, and the coordinates are followed by a slash and the dimension of the mapped area in minutes; for example, "/60x120" follows the coordinates. The coordinates that identify the map are of the corner closest to $0^{\circ}$ latitude and $0^{\circ}$ longitude. Note that while the length of the coordinate entries in the 1:24,000-scale state and territory files is fixed, the length of the coordinate entries in the 1:100,000- and 1:250,000-scale map file is variable because the dimension in minutes of latitude and longitude may vary.

COUNTY - A variable-length alphabetic entry containing the name of the major civil division (county equivalent) or civil divisions in which the topographic map is located.

FIPS - A fixed-length numerical element that contains the two-digit FIPS code for states and territories. This element is available only in the file that identifies 1:100,000-scale and 1:250,000-scale maps.

HIST - The data presented are variable length and include any information of historical significance regarding the map, especially former names.

MAP - A four-digit number assigned to each 7.5-minute cell in each state and territory. Overedge maps are divided into two complete 7.5-minute maps with valid numbers, and 7.5-minute cells totally in water are also assigned valid numbers. The numbering system begins with the number 1 in the northwest corner of each state and territory and increases consecutively by moving from west to east while progressing latitudinally southward. This numbering system was designed specifically to code geographic names to individual topographic maps. Since the geographic names were compiled on a State-by-State basis, each State's map numbering system begins with the number 1 , thereby creating controlled redundancy in the numbering system. Some 15-minute maps and 1:250,000-scale maps were assigned numbers depending upon whether a state was completely covered by 7.5-minute published topographic maps at the time of Phase I compilation of the National Geographic Names Data Base. The beginning number for 15-minute maps and 1:250,000-scale maps varies from state to state. Map records in the 15-minute and 1:250,000-scale topographic map series are present in the state and territory topographic map files only if they were needed for geographic name compilation. Complete coverage for $1: 250,000-s c a l e$ maps may be found in one file; however, complete 1:62,500scale coverage does not exist in any GNIS file.

NAME - A variable-length alphanumeric entry that represents the full name of the 7.5-minute cell as it appears on the published topographic map. Some entries will contain the word "SEE" followed by a 7.5-minute cell name. This is necessary because each state or territory is divided into 
equal 7.5-minute cells (except Alaska), and many 7.5-minute maps are published as overedge maps, which means that small portions of land outside the normal 7.5-minute bounds of the map are included. Overedge areas are treated as a separate 7.5-minute cell having no approved name, and must be referenced to the main 7.5-minute map which portrays the overedge area. Additionally, some special 1:24,000-scale maps are designed to show oddly shaped areas, such as Isle Royal in Michigan. These areas have also been divided into as many 7.5-minute cells as necessary with each cell name a reference to the main map, except the southeast corner 7.5-minute cell which bears the actual name of the main map. Also, some entries contain the reference "(ALL WATER)" which indicates that the particular 7.5-minute cell is completely covered with water. Note that in the individual state and territory files, all available 15-minute or 1:250,000-scale quadrangles are not present. Those that are present are there only because there was no larger scale coverage at the time Phase I of the National Geographic Names Data Base was compiled. A complete listing of the names of $1: 100,000-$ scale and $1: 250,000$-scale quadrangles may be retrieved from one national file, but there is no complete coverage of the 15-minute series in any GNIS file.

NUMBER - An eight-digit number that is the unique identifier of each entry (quadrangle name) and its associated information. The first two digits correspond to the state numeric FIPS code. The first two digits of the eight-digit entries for the file that identifies 1:100,000-scale and $1: 250,000-$ scale maps are 00 . This element is for use by GNIS staff.

QUAD - A fixed-length field containing the first eight characters of the USGS code for each 7.5-minute quadrangle in the United States. The entire United States (except Alaska and outlying areas) is divided into areas of $1^{\circ}$ latitude $x 1^{\circ}$ longitude each containing sixty-four 7.5-minute quadrangles. The rows within each area are coded $A$ through $H$, and the columns are coded 1 through 8 each beginning in the southeast corner of the $1^{\circ} \mathrm{x}$ $1^{\circ}$ area. The first five characters are the same for each of the 64 quadrangles within the area and are determined by the geographic coordinates (degrees) representing the southeast corner of the $1^{\circ} \times 1^{\circ}$ area. These five digits are followed by a hyphen and the appropriate row-column designation. This is not the complete quadrangle code, but it is sufficient to identify the 7.5-minute topographic map.

SCALE - Generally a two-character numeric entry which indicates the ratio of unit length on the map to unit length on the Earth, and identifies the particular series to which the map belongs. In the state and territory files the entry is fixed at two numbers. Six entries are possible: 20, $24,25,62,63$, and 88 . A code of 20 indicates metric topographic maps in Puerto Rico, 24 indicates 7.5-minute 1:24,000-scale maps in English units, and 25 indicates either 7.5-minute or 7.5- x 15-minute maps in metric units at a scale of 1:25,000. A code of 62 indicates 15-minute maps at a scale of $1: 62,500$, and 63 is used (mostly) for $1: 63,360$-scale maps in Alaska. An 88 identifies maps in the 1:250,000-scale series in the state and territory files and was used because the field was limited to two characters. The scales in the file that identifies 1:100,000scale and 1:250,000-scale maps are six digits, either 100000 or 250000 . 
STATE - The entries in this element are of two types. One type is used in the state and territory files and is the two-character alphabetical FIPS code. The other type, used in the file that identifies 1:100,000 scale and 1:250,000-scale maps, is the State abbreviation from the Government Printing office style Manual as shown on topographic maps. The style manual abbreviations contain periods, and multiple state entries are separated by hyphens.

XNAME - A variable-length alphabetic element for the names of maps in the USGS 7.5- $x$ 15-minute map series. Since the 7.5- x 15-minute map generally spans the same area as two 7.5- x 7.5-minute maps, the east half containing the southeast corner coordinate contains the name of the 7.5$x$ 15-minute map, while the west half contains the word "SEE", followed by the name of the 7.5- x 15-minute map.

250 - The entries are variable length and are limited to the 1:100,000scale maps. The information contained in this element associates the $1: 100,000$-scale mapname to the appropriate quadrant of the $1: 250,000-$ scale map. The entry consists of the 1:250,000-scale mapname followed by the appropriate directional; NE, SE, NW, or SW.

\section{Reference Data Base}

The Reference Data Base is designed for use as a research and reference tool as well as a depository of reference information for GNIS. There are currently two files in this data base. One file contains the 63 broad feature categories of the National Geographic Names Data Base, definitions of those categories, and their cross-references to all generics or types of features found on topographic maps and other sources. The file also contains detailed information concerning unusual generics, such as specifically where they are found, how they are used, and if possible, why they were applied in such an unusual manner. Other information includes official abbreviations of generics used on topographic maps. The second file contains the complete annotated bibliographies of all source material (in addition to USGS topographic maps) used in the compilation of the National Geographic Names Data Base.

The following data element descriptions are designed to provide the necessary information for understanding and retrieving data. Table 3 lists each data element and the appropriate label used when retrieving data.

ABBREV - A variable-length alphabetic field containing the standard abbreviations used on USGS topographic maps.

BIBLIO - A variable-length alphabetic field containing the complete annotated bibliographic entry and associated code for all source material other than USGS topographic maps used in geographic names compilation. The code for the bibliographic entry is used in the data element BIBLIO in the National Geographic Names Data Base, and the first two characters are the State alphabetic FIPS code, followed by a hyphen and an $M$ or $T$ corresponding to map or text respectively. The $M$ or $T$ is followed by one or more digits that is a cross-reference to the same code used with entries in the National Geographic Names Data Base. The code is followed 
Table 3.--Labels and data elements from the Reference Data Base

\begin{tabular}{ll}
\hline Label & \multicolumn{1}{c}{ Data Element } \\
\hline ABBREV & $\begin{array}{l}\text { STANDARD ABBREVIATION } \\
\text { ANNOTATED BIBLIOGRAPHY OF } \\
\text { SOURCE MATERIALS }\end{array}$ \\
DEF & FEATURE CLASS DEFINITION \\
DESIG & GNIS FEATURE CLASS \\
HIST & GENERIC SOURCE, TYPE, AND USE \\
NUMBER & ID NUMBER \\
PRIME & PRIMARY COORDINATE LOCATION \\
SOURCE & SOURCE COORDINATE NECESSARY \\
WORD & GENERIC NAME SHOWN ON MAP \\
\hline
\end{tabular}

by a dash and the bibliographic citation and appropriate annotation regarding the content of the source. Some entries begin with the characters US which means that this source is used nationally.

DEF - A variable-length alphabetic field providing the GNIS definition of each of the broad feature class categories contained in the data element DESIG. It provides the basis for classifying broad categories of features.

DESIG - A variable-length, lower-case element that is designed to group similar features into broadly designated categories to facilitate search and retrieval of feature types.

HIST - A variable-length alphabetic field containing unusual generics (see data element "WORD"). Each entry lists the map on which the generic is used, how it is used, to what it refers specifically, the general category into which it is grouped, reason for use (if discernible), and other pertinent information that would aid in research or application. The same generic may refer to different types of features throughout the country . All unusual applications of the same generic are listed together no matter how diverse the feature types.

NUMBER - An eight-digit number that is the unique identifier of each record and its associated information. This data is for GNIs internal use.

PRIME - A variable-length field containing lower-case entries that specifically state where the primary coordinates of feature types in the National Geographic Names Data Base are to be digitized.

SOURCE - Contains the lower-case word "yes" if the generic or feature class indicates a linear feature, thereby requiring source coordinates.

WORD - A variable-length upper- and lower-case entry that represents the generic or type of feature. This data element serves multiple purposes. It provides a relationship and reference to a feature type with one of 
the broad categories of terms used to classify features in the National Geographic Names Data Base (see data element "DESIG"). It is also a record of all generics encountered on all source material used in the compilation of other data bases. This data element provides a means of discovering and researching subtle differences in feature types.

\section{Board on Geographic Names Data Base}

The Board on Geographic Names Data Base contains information representing the investigations and decisions of the Domestic Names Committee of the U.S. Board on Geographic Names. The Board was created in 1890 and established in its present form by Public Law in 1947. The Board is authorized to establish and maintain uniform geographic name usage throughout the Federal government, and the Board also currently maintains a close working relationship with names authorities in about 30 states. The staff of the Board researches the background of geographic names that are determined to be in conflict on Federal sources or are controversial in nature. The results of the research are promulgated in a quarterly report, and these decisions are binding for Federal usage. Most State and local usage follows the recommendations of the Board.

Each entry in this data base may also be found in the National Geographic Names Data Base; however, the entries here contain the reference and associated detailed information researched and promulgated by the U.S. Board on Geographic Names. The data base reflects all of the activity of the Board from 1890 through the first quarter of 1959 . The remainder of the data base is scheduled for completion at a later date.

The following data element descriptions are designed to provide the necessary information for understanding and retrieving data. Table 4 lists each data element and the appropriate label used when retrieving data.

Table 4.--Labels and data elements from the Board on Geographic Names Data Base

\begin{tabular}{ll}
\hline Label & Data Element \\
\hline BGN & \\
DESCR & BGN DECISION \\
DESIG & DESCRIPTION \\
ELEV & TYPE OF FEATURE \\
GENRE & ELEVATION (FT) \\
HEADS & GENERIC \\
HIST & SOURCE OR FEATURE (LATLONG) \\
LATLONG & HISTORICAL NOTE \\
LOC & GEOGRAPHIC COORDINATES \\
NAME & STATE/COUNTY FIPS CODE \\
NUMBER & FEATURE NAME \\
SIZE & ID NUMBER \\
STATE & SIZE \\
VAR & NAME OF STATE (FIPS) \\
& VARIANT NAME(S) \\
\hline
\end{tabular}


BGN - A variable-length alphanumeric field that represents the year a decision was rendered by the BGN because the name required special research and action. A special entry is the word "Statutory", followed by a space and the year a name was designated by an act of Congress. Another special entry is the word "Vacated", followed by a space and a year. This indicates that the feature no longer exists or the name is no longer in use. There may be multiple dates for the same name with multiple data entries separated by semicolons.

DESCR - A variable-length field providing upper- and lower-case text that defines the situation or relative position to nearby features and to at least one close well-known feature, usually a major town or city. Distances are provided as well as all major and minor civil division names associated with the feature. Information prior to 1950 is sketchy and in many cases nonexistent.

DESIG - A variable-length lower-case alphabetical element that is designed to group similar features into broadly designated categories to facilitate search and retrieval. The Reference Data Base contains a cross-reference to one of these categories for every generic thus far encountered in the compilation of the data base.

ELEV - A variable-length numeric field that gives the height above or depth below mean sea level, in feet, of the highest or lowest point respectively of the feature. Negative elevations are preceded by a minus sign. Some elevations indicate a range; for example, 1000-5000.

GENRE - A variable-length alphabetic field referring to the generic portion of a name that usually identifies the kind of feature. However, it may be a false generic that is directly related to subjectivity in the naming process; for example, Big River, which is a populated place and not a river. The generic may indicate very subtle differences in feature types, but care should be taken because the naming process includes a great deal of subjectivity including whimsical and direct misnaming.

HEADS - A 15-character alphanumeric field provided to indicate the source of linear features. The format is identical to the geographic coordinates in LATLONG. The source of a linear feature is not always indicated by the name placement on the map; therefore, the guideline applied was that the source of linear features not properly identified by name placement or textual description should be taken to the source of the longest, straightest drain in accordance with BGN policy.

HIST - A variable-length upper- and lower-case text that provides as much information as is available from reputable sources about the physical and cultural history of a named feature. Additionally, special attention is given to name origin if known, and information is provided for background research. Information prior to 1950 is sketchy and in most cases nonexistent.

LATLONG - The official geographic coordinate of the feature compressed and fixed at 15 characters. Latitude and longitude are to degrees, minutes, and seconds with each followed by a one-character alpha directional indicator. If the degrees of longitude are less than 100, a leading zero is 
present. In the case of areal features, the coordinates are the approximate center of the feature, while linear features are represented at the mouth. The mouth is where the feature joins another feature, ends in a delta or is an alluvial fan, or no longer has a discernible channel or trough-like character. The guideline for areal features requires that coordinates be taken in the center, but the location of the center of a large city is sometimes somewhat subjective. Additional guidelines for determining the placement of geographic coordinates for large populated places are the location of the city hall or town hall, main post office, main library, central business district, or main intersection.

LOC - A variable-length alphanumeric field that contains one or more fivedigit FIPS codes referring to the state and county. The first two digits refer to the state or territory and the last three refer to the county, parish, municipio, or other civil division. Codes for all counties in which a feature is located are present, with multiple entries separated by semicolons. All codes are numeric except when the state or territory borders a foreign country, in which case the appropriate two-character, alphabetical FIPS code is used -- CA for Canada, MX for Mexico, UR for the Soviet Union, UK for the United Kingdom, and WS for Western Samoa.

NAME - A variable-length upper-and lower-case alphanumeric entry that contains the official name, which in most cases includes a generic which indicates the feature type. Some entries are followed by a space and an asterisk which denotes a diacritical mark somewhere in the name. This arrangement is temporary and will soon be replaced by the inclusion of the appropriate diacritical mark and the removal of the asterisk. In some cases the generic may be in the first position, followed by the specific part of the name. In those cases, the position of the generic within the name is generally reversed; for example, Mount Saint Helens becomes Saint Helens, Mount. The generic, however, is not reversed if the feature is a populated place or if the specific part of the name contains an Arabic number. Additionally, if the definite article occurs in initial position in the name, it is reversed; for example, The Plains becomes Plains, The, and La Mesa becomes Mesa, La. Abbreviations are always spelled out completely and Arabic numerals are usually transcribed as full words.

NUMBER - An eight-digit number that is the unique identifier of each record and its associated information. This data element is for GNIS staff use.

SIZE - A short variable-length phrase that gives the length of linear features and the width of areal features in English units.

STATE - A two-character alphabetical element containing the FIPS code for States and territories. Multiple data items are not present; if the extent of the feature includes more than one state, the code is that of the State where the center or mouth is located.

VAR - A variable-length upper- and lower-case field containing any other known names or other spellings of the current official name. If more than one variant name is present, they are arranged alphabetically and 
separated by commas and a blank. Additionally, if the BGN rendered a formal decision for what is now a variant, the year of that decision is given in parentheses following the variant name with which it is as sociated.

\section{ORDERING INFORMATION}

Questions regarding the structure of GNIS, other technical matters, or individualized search possibilities should be addressed to:

Manager, GNIS

U.S. Geological Survey

523 National Center

Reston, Virginia 22092

(703) 648-4544/FTS 959-4544

Questions regarding changing the names of features or proposing new names for features should be addressed to:

Executive Secretary, Domestic Names Committee

U.S. Board on Geographic Names

U.S. Geological Survey

523 National Center

Reston, Virginia 22092

Standard products and specialized searches may be ordered from any of the regional information offices of the U.S. Geological Survey listed below.

National Headquarters National Cartographic

Information Center U.S. Geological Survey 507 National Center Reston, VA 22092 (703) 860-6045/

FTS $928-6045$

\section{National Cartographic}

Information Center U.S. Geological Survey National Space Technology

Laboratories, Bldg. 3101 NSTL Station, MS 39529 (601) 688-3544/

FTS $494-3544$

EROS Data Center

U.S. Geological Survey

Sioux Falls, SD 57198

(605) 594-6151/

FTS 784-7151

\section{Mid-Continent Mapping} Center-NCIC

U.S. Geological Survey 1400 Independence Road Rolla, MO 65401

(314) 341-0851/

FTS 277-0851

\section{National Cartographic} Information Center U.S. Geological Survey Skyline Building

218 E street Anchorage, AK 99501 ( 907 ) 271-4159/ FTS 271-4159

\author{
Western Mapping Center- \\ NCIC \\ U.S. Geological Survey \\ 345 Middlefield Road \\ Menlo Park, CA 94025 \\ (415) 329-4309 \\ FTS 459-4309
}

Rocky Mountain Mapping Center-NCIC

U.S. Geological Survey

Box 25046, Stop 504

Federal Center

Denver, CO 80225

(303) 236-5829/

FTS $776-5829$ 
Official State Gazetteers must be ordered from:

\author{
Western Distribution Branch \\ U.S. Geological Survey \\ Books and Open-File Reports \\ Federal Center, Bldg. 41 \\ Box 25425 \\ Denver, CO 80225
}

Standard products include interim listings of geographic names in each State arranged in alphabetical order. These reports are strip bound and vary from one to three volumes per state. Microfiche in the same format as the interim reports are also available. Reports may be generated from specialized searches of GNIS, and the cost varies depending upon the nature of the search. Interim products contain only geographic names found on the topographic maps published by the U.S. Geological survey.

For more complete listings of geographic names one should refer to the official state Gazetteer if available. The gazetteer contains all of the names in the interim listings plus names from other Federal, State, and local sources as well as historical materials. Variant names are included in their proper alphabetical sequence cross-referenced to their appropriate official name. A variant name is any other known name or spelling (current or historical) applied to a feature. Please contact the GNIS Manager regarding the availability of Gazetteers and forthcoming editions.

Magnetic tapes may be purchased in either the standard format or for specialized searches and may be written to most technical specifications. If a choice is not specified by the user, the tape will be written as follows :

1600 bpi

EBCDIC code

a logical record length of 248

a block size of 4960

Fixed-block record format

IBM standard label 
APPENDIXES 
APPENDIX A.--Categories of Named Features not yet included in the Geographic Names Information System

Phase I

Generally, all named features on the most current largest scale USGS topographic maps were included for Phase I compilation. Some categories of named features, however, were omitted from Phase I because more complete lists of these categories were available from other sources. If a State or territory has only been completed through Phase I, the following categories of named features will not be present:

airports, radio and television station towers, federally administered areas greater than 30 square miles, major and minor civil divisions, some major features that are too large to be named on 7.5-minute, $1: 24,000$-scale topographic maps, regional names, historical names, most building names, roads and highways.

Phase II

Available information from the categories not compiled during Phase $I$, as well as geographic names from other sources, are added during Phase II. If a state or territory has been completed through Phase II compilation, information for all known, named features should be present except for:

roads and highways. 


\section{APPENDIX B.--Geograpinic Names Information System (GNIS) Feature Class Definitions}

The feature class terms and abbreviations currently consist of nine or fewer letters and were chosen for computer search and retrieval purposes. They do not necessarily represent terminology for the identification of all kinds of cultural and natural features. Although some of the terms may agree with dictionary definitions, they represent more generalized categories. Some commonly used generics are listed in parentheses at the end of each entry to assist in understanding the range of cultural and natural entities represented by the term. Refer to the Reference Data Base to retrieve all generics thus far encountered in geographic names compilation. In most instances a plural form is listed as if it were singular; for example, archipelago or islands would be categorized as island. The terms and the definitions are as follows:

airport - manmade facility maintained for the use of aircraft (airfield, airstrip, landing field, landing strip).
arch - natural arch-1ike opening in a rock mass (bridge, natural bridge, sea arch).
area - any one of several areally extensive natural features not included in other categories (badlands, barren, delta, fan, garden).
arroyo - watercourse or channel through which water may occasionally flow (coulee, draw, gully, wash).
bar - natural accumulation of sand, gravel, or alluvium forming an underwater or exposed embankment (ledge, reef, sandbar, shoal, spit).

basin - natural depression or relatively low area enclosed by higher land (amphitheater, cirque, pit, sink).

bay - indentation of a coastline or shoreline enclosing a part of a body of water; a body of water partly surrounded by land (arm, bight, cove, estuary, gulf, inlet, sound).

beach - the sloping shore along a body of water that is washed by waves or tides and is usually covered by sand or gravel (coast, shore, strand).

bench - area of relatively level land on the flank of an elevation such as a hill, ridge, or mountain where the slope of the land rises on one side and descends on the opposite side (leve1).

bend - curve in the course of a stream and (or) the land within the curve; a curve in a linear body of water (bottom, loop, meander). 
APPENDIX B.--Geographic Names Information System (GNIS)

Feature Class Definitions (continued)

\begin{abstract}
bridge - manmade structure carrying a trail, road, or other transportation system across a body of water or depression (causeway, overpass, trestle).
\end{abstract}

building - a manmade structure with walls and a roof for protection of people and (or) materials, but not including church, hospital, or school.

canal - manmade waterway used by watercraft or for drainage, irrigation, mining, or water power (ditch, lateral).

cape - projection of land extending into a body of water (lea, neck, peninsula, point).

cave - natural underground passageway or chamber, or a hollowed out cavity in the side of a cliff (cavern, grotto).

cemetery - a place or area for burying the dead (burial, burying ground, grave, memorial garden).

channel - linear deep part of a body of water through which the main volume of water flows and is frequently used as a route for watercraft (passage, reach, strait, thoroughfare, throughfare).

church - building used for religious worship (chapel, mosque, synagogue, tabernacle, temple).

civil - a political division formed for administrative purposes (borough, county, municipio, parish, town, township).

cliff - very steep or vertical slope (bluff, crag, head, headland, nose, palisades, precipice, promontory, rim, rimrock).

crater - circular-shaped depression at the summit of a volcanic cone or one on the surface of the land caused by the impact of a meteorite; a manmade depression caused by an explosion (caldera, lua).

crossing - a place where two or more routes of transportation form a junction or intersection (overpass, underpass).

dam - water barrier or embankment built across the course of a stream or into a body of water to control and (or) impound. the flow of water (breakwater, dike, jetty).

falls - perpendicular or very steep fall of water in the course of a stream (cascade, cataract, waterfall).

flat - relative level area within a region of greater relief (clearing, glade, playa). 
APPENDIX B.--Geographic Names Information System (GNIS)

Feature Class Definitions (continued)

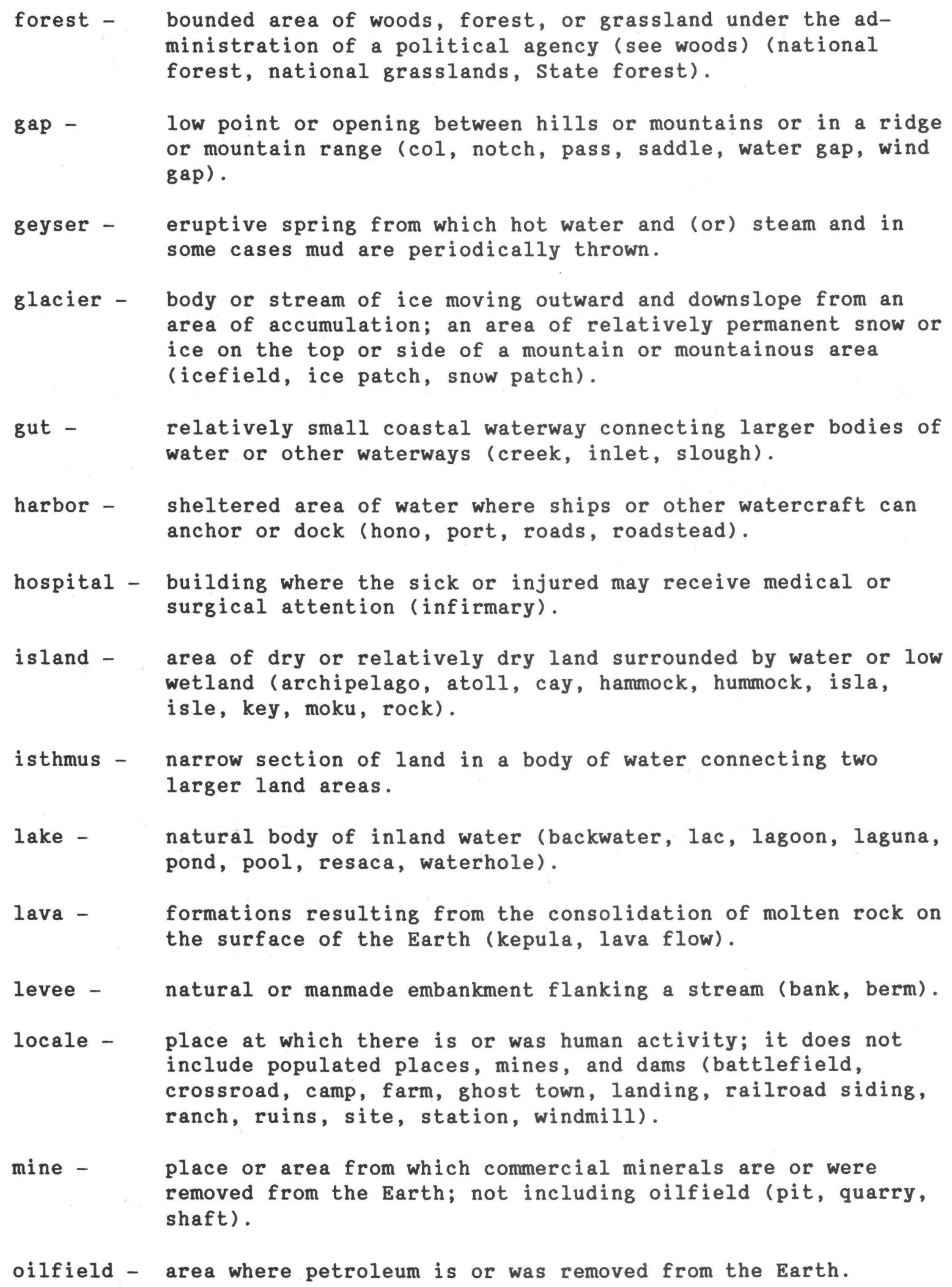


APPENDIX B.--Geographic Names Information System (GNIS)

Feature Class Definitions (continued)

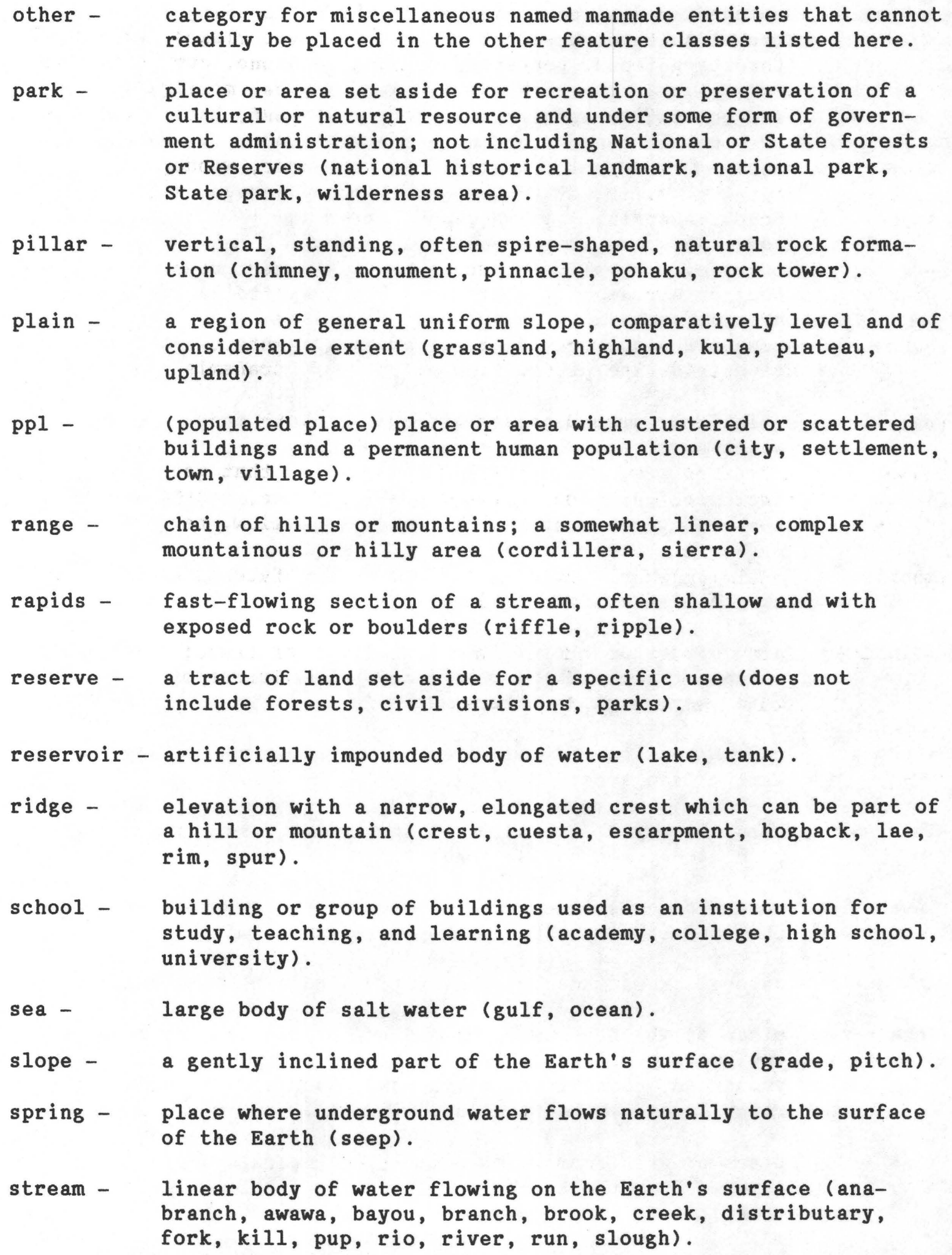


APPENDIX B.--Geographic Names Information System (GNIS)

Feature Class Definitions (continued)

summit -

swamp -

trail -

tower -

tunnel -

valley -

wel1 -

woods - prominent elevation rising above the surrounding level of the Earth's surface; does not include pillars, ridges, or ranges (ahu, berg, bald, butte, cerro, colina, cone, cumbre, dome, head, hill, horn, knob, knoll, mauna, mesa, mesita, mound, mount, mountain, peak, puu, rock, sugarloaf, table, volcano).

poorly drained wetland, fresh or saltwater, wooded or grassy, possibly covered with open water (bog, cienega, marais, marsh, pocosin).

route for passage from one point to another; does not include roads or highways (jeep trail, path, ski trail).

a manmade structure, higher than its diameter, generally used for observation, storage, or electronic transmission.

linear underground passageway open at both ends.

linear depression in the Earth's surface that generally

slopes from one end to the other (barranca, canyon, chasm, cove, draw, glen, gorge, gulch, gulf, hollow, ravine).

manmade shaft or hole in the Earth's surface used to obtain fluid or gaseous materials.

small area covered with a dense growth of trees; does not include an area of trees under the administration of a political agency (see forest). 
APPENDIX C.--Parenthetical Descriptors used with Names

The following terms have been used on USGS topographic maps and other sources to provide additional information or clarity about the name or the feature to which the name refers.

\author{
Abandoned \\ Active Mine \\ Alkali \\ Archaeological Site \\ BLM - refers to Bureau \\ of Land Management \\ Campground \\ Cemetery \\ Diabase Dike \\ Dry spring \\ Flowing \\ Foot Bridge \\ Ghost Town \\ Historic \\ Historical \\ Historical Monument \\ Historical Ruins \\ Historic Site \\ Inactive Mine \\ Jeep Trail \\ Mud \\ Natural Arch \\ oil Field \\ old Channel
}

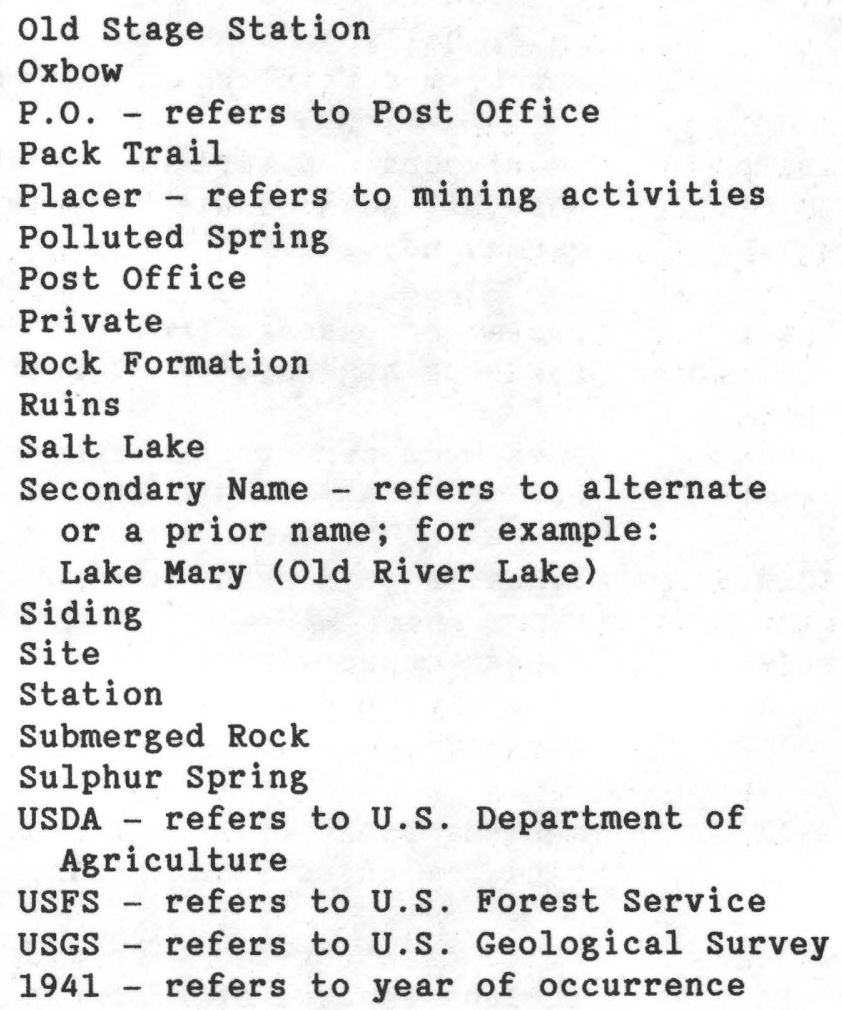


APPENDIX D.--Sample Records from the National Geographic Names Data Base

Sample 1

ID NUMBER - 34003474

NAME - Jersey City

TYPE OF FEATURE - pp1

FEDERAL STATUS - BGN 1931

COUNTY NAME - Hudson

STATE/COUNTY FIPS CODE - 34017

GEOGRAPHIC COORDINATES - 404341N0740441W 404508N0740225W

MAP OR CHART NAME - Jersey City, Bayonne

USGS QUADRANGLE CODE - 40074-F1 40074-H1

ELEVATION (FT) - 83

VARIANT NAME(S) - Hudson, Paulus Hook, Powles Hook

STATE - NJ

Sample 2

ID NUMBER - 34003631

NAME - Kittatinny Mountain

TYPE OF FEATURE - summit

FEDERAL STATUS - BGN 1938

COUNTY NAME - Warren, Bergen, Adams (PA), Burlington

STATE/COUNTY FIPS CODE - 34041340374208936071

GEOGRAPHIC COORDINATES - 411915N0743943W 410106N0750159W $410435 \mathrm{~N} 0745605 \mathrm{~W}$ 410741N0745241W $411010 \mathrm{~N} 0744758 \mathrm{~W}$ 411355N0744202W

MAP OR CHART NAME - Portland, Big Creek, High Mountain, Bergens Mountain, Rapidan River, Blue Level

USGS QUADRANGLE CODE - 40074-H1 40074-A2 40074-A3 40074-B1 40074-B2 40074-D6

ELEVATION (FT) - 1549

VARIANT NAME(S) - Blue Mountains, Kittatinny Mountain Range, Kittatinny Mountains

STATE - NJ

Sample 3

ID NUMBER - 34009173

NAME - Franklin Park

TYPE OF FEATURE - pP1

FEDERAL STATUS - BGN

COUNTY NAME - Burlington

STATE/COUNTY FIPS CODE - 34005

GEOGRAPHIC COORDINATES - 400130N0745430W

MAP OR CHART NAME - Beverly

GNIS MAP NO - 0090

USGS QUADRANGLE CODE - 40074-A8

ELEVATION (FT) - 40

VARIANT NAME(S) - Strawberry Hill

BIBLIOGRAPHIC CODE - NJ-M2

STATE - NJ 
APPENDIX D.--Sample Records from the National Geographic Names Data Base (continued)

\section{Sample 4}

ID NUMBER - 34009182

NAME - Pisgah, Mount

TYPE OF FEATURE - summit

FEDERAL STATUS - BGN

COUNTY NAME - Burlington

STATE/COUNTY FIPS CODE - 34005

GEOGRAPHIC COORDINATES - 400038N0744024W

MAP OR CHART NAME - Columbus

GNIS MAP NO - 0092

USGS QUADRANGLE CODE - 40074-A6

ELEVATION (FT) - 186

VARIANT NAME(S) - The Old Weavers Hill

BIBLIOGRAPHIC CODE - NJ-T3/p. 34

STATE - NJ

Sample 5

ID NUMBER - 34001385

NAME - Cohansey River

TYPE OF FEATURE - stream

FEDERAL STATUS - BGN 1954

COUNTY NAME - Cumberland, Bergen

STATE/COUNTY FIPS CODE - 3401134033

GEOGRAPHIC COORDINATES - 392039N0752127W 392230N0752057W

$392237 \mathrm{~N} 0751500 \mathrm{~W}$

SOURCE OF FEATURE (LATLONG) - 393356N0751613W

MAP OR CHART NAME - Ben Davis Point, Old Mill, Hansoms Hill, Big Gap USGS QUADRANGLE CODE - 39075-C3 39075-A2 39075-B1 39075-A4

VARIANT NAME(S) - Cohansey Creek, Cohanzey Creek, Cohanzy Creek

STATE - NJ 